\title{
A Cross-Linked Polymer Soil Stabilizer for Hillslope Conservation on the Loess Plateau
}

\author{
Xiaochao Zhang ${ }^{1,2}$, Yujian Zhong ${ }^{1,2 *}$, Xiangjun Pei ${ }^{1,2}$ and Yuying Duan ${ }^{1}$ \\ ${ }^{1}$ State Key Laboratory of Geological Disaster Prevention and Environmental Protection, Chengdu University of Technology, \\ Chengdu, China, ${ }^{2}$ State Environmental Protection Key Laboratory of Synergetic Control and Joint Remediation for Soil and Water \\ Pollution, School of Ecological and Environmental Sciences, Chengdu University of Technology, Chengdu, China
}

OPEN ACCESS

Edited by:

Fanyu Zhang,

Lanzhou University, China

Reviewed by:

Tongwei Zhang,

Lanzhou University, China

Fangzhou Liu,

University of Alberta, Canada

*Correspondence: Yujian Zhong

zhongyujian@stu.cdut.edu.cn

Specialty section:

This article was submitted to

Geohazards and Georisks,

a section of the journal

Frontiers in Earth Science

Received: 06 September 2021 Accepted: 30 September 2021

Published: 14 October 2021

Citation:

Zhang $X$, Zhong $Y$, Pei $X$ and Duan $Y$

(2021) A Cross-Linked Polymer Soil Stabilizer for Hillslope Conservation on the Loess Plateau.

Front. Earth Sci. 9:771316. doi: 10.3389/feart.2021.771316
The soil of the Loess Plateau is highly susceptible to erosion due to its distinct loess structure with poor water stability and disintegrates easily. Previous research has focused on improving soil strength without considering stability and ecological performance. Comprehensive improvements may be achieved by cross-linked polymers (CLPs), but their effect on loess structure remains unclear. In the present study, we investigate CLPs as a new organic soil stabilizer to improve soil aggregate stability. To determine the effect of CLPS on the stabilization of loess, a series of indoor tests was conducted to assess unconfined compressive strength, water stability, soil-water characteristics, and plant height. The stabilization mechanism was analyzed by comparing the microstructure, mineral composition, and features of functional groups of loess before and after treatment. The results showed that, compared with untreated loess, the unconfined compressive strength and anti-disintegration property of treated loess were significantly increased. The water retention capacity was improved, and the germination rate and growth of plants were promoted. Microscopic analysis showed that the use of CLPs did form new minerals in the loess or change the functional groups, rather, CLPs improved the microstructure, reduced the total volume of pores, and increased the degree of soil compaction. Field tests showed that the erosion of loess hillsides was effectively controlled by CLPs. Under the same erosive conditions, the slope surface treated with CLPs was more intact than the untreated slope surface. Our findings provide new strategies regarding the application of CLPs as soil stabilizers to control loess erosion and promote vegetation restoration.

Keywords: cross-linked polymer, soil stabilizer, loess, erosion control, curing mechanism, mechanical property

\section{INTRODUCTION}

Loess is rich in calcium and soluble salts; its structure is loose, cementation is weak, and large pores and vertical joints develop. Under rainfall or irrigation, the integrity and stability of loess without vegetation cover are easily damaged, which may cause various disasters, such as collapse, landslide, and debris flow (Peng et al., 2018; Feng et al., 2020). With more intensive construction on the Loess

\footnotetext{
Abbreviations: CLPs, cross-linked polymers (stabilizer); CMC, carboxymethylcellulose; FTIR, Fourier-transform infrared; PAM, polyacrylamide; SWCC, soil-water characteristic curve; SEM, scanning electron microscopy; UCS, unconfined compressive strength; XRD, X-ray diffraction
} 
Plateau, exposed slopes have been produced, causing serious soil erosion (Hu et al., 2020; Wu et al., 2020).

The factors influencing soil erosion on loess slopes can be summarized into four categories: rainfall, soil erodibility, topography, and slope surface cover (Liu et al., 2019). By reducing the slope (Zhao et al., 2015; Li et al., 2019) and setting buffer steps (Duan et al., 2021a; Wen et al., 2021), we can effectively reduce the kinetic energy of runoff and control rill erosion (Wei et al., 2007; Fu et al., 2009; Zhao et al., 2013; Tang et al., 2020). For slope surface cover, erosion control can be achieved by, for example, planting trees and grass (Chen et al., 2018; Yan et al., 2021) or laying artificial turf (Li et al., 2020). However, there remain challenges associated with implementing these physical measures, such as large engineering volume, complicated construction, and incomplete erosion control. Furthermore, such measures mainly strengthen the macroscopic structure of the slope, but they fail to alter the soil properties. For the problem of loess erosion, the microstructure of loess can be fundamentally improved by stabilizers to improve soil stability.

Soil stabilizers can be divided into calcium-based stabilizers and non-calcium-based stabilizers according to composition (Behnood, 2018; Jalal et al., 2020). Studies have shown that calcium-based stabilizers, such as lime (James, 2020), gypsum (Ahmeda and Issa, 2014), fly ash (Xu et al., 2019; Yoobanpot et al., 2020), cement (Choobbasti and Kutanaei, 2017), and ground granulated blast furnace slag (GGBFS) (Keramatikerman et al., 2016), significantly enhance the compressive and shear strength. Indeed, this kind of stabilizer offers an effective measure to increase the bearing capacity of foundations. However, the abovementioned techniques are inapplicable to soil conservation, since such measures cause excessive hardening of the soil. Moreover, the use of traditional calcium-based stabilizers in soil stabilization projects leads to ecological damage, including the consumption of energy and resources, increasing $\mathrm{pH}$, and high $\mathrm{CO}_{2}$ emissions. Non-calcium-based soil stabilizers are more suitable for controlling hillslope erosion owing to their lower concentration and stability strength. Such stabilizers have achieved soil reinforcement (Zhang T. et al., 2020), improved the degree of compaction (Kushwaha et al., 2018; Mohammad and Eris, 2020), and increased soil aggregation (Ghasemzadeh and Modiri, 2020), which manifests as an increase in mechanical strength. Some non-calcium-based stabilizers can alter the form and distribution of water in soil (Chandler et al., 2017), thereby reducing soil erodibility. Indoor and outdoor rainfall simulation experiments have demonstrated the feasibility of using non-calcium-based stabilizers to prevent or control erosion (Song et al., 2019; Krainiukov et al., 2020). Different non-calcium-based stabilizers have different benefits in terms of seed germination, seedling growth, and long-term plant growth (Liu et al., 2011; Chang et al., 2015; Yang et al., 2019).

Loess is more susceptible to erosion than many other soils, resulting in lower vegetation coverage and fragile ecological environments on the Loess Plateau. For the effective use of soil stabilizers to control loess hillslope erosion, the overall performance must be considered, including soil stability, plant compatibility, and water-retention capacity. Most previous research focused on optimizing soil strength, and there remains a lack of more comprehensive research considering stability and ecological performance. Such comprehensive improvements may be achieved by grafting with a polyacrylamide (PAM), containing amide groups, and carboxymethylcellulose (CMC), containing several hydroxyl groups. Both CMC and PAM can effectively stabilize the soil while improving the water-retention capacity (Ozan et al., 2018). $\mathrm{CMC}$ is used as agricultural water retention additive, which can improve soil water retention capacity, but its solution viscosity is limited due to low molecular weight. PAM can make up for the lack of viscosity because of the larger molecular weight. The high viscosity solution formed by PAM solution due to flocculation and high molecular weight can effectively stabilize the soil. By crosslinking and polymerization, the viscosity increases with the increase of molecular weight, and has the excellent water retention performance of CMC. In the present study, a new type of dual CLP was synthesized using the abovementioned method. The application benefits of this new curing agent in loess erosion control were evaluated comprehensively.

\section{MATERIALS AND METHODS}

To determine whether CLPs improve the engineering performance of loess, the unconfined compressive strength (UCS), disintegration, and soil-water characteristic curve (SWCC) were determined, and a pot experiment was carried out on untreated and CLP-treated loess. To explain the stabilization mechanism, the effects of CLPs on loess particles, pore characteristics, mineral composition, and functional groups were studied through scanning electron microscopy (SEM), X-ray diffraction (XRD), and Fouriertransform infrared spectra (FTIR).

\subsection{Materials}

The loess used in this study was obtained from a land excavation slope in Yanan, Shaanxi Province, China. The coordinates of the sampling point are $109^{\circ} 19^{\prime} 25^{\prime \prime} \mathrm{E}$ and $36^{\circ} 36^{\prime} 00^{\prime \prime} \mathrm{N}$. The sampling site is shown in Figure 1. Owing to rainfall and soil erosion on both sides of the drainage ditch, many erosive rills were formed on the hillside, and collapse was evident. The physical properties of loess were: natural water content, $12.77 \%$; soil natural density, $1.6 \mathrm{~g} \mathrm{~cm}^{-3}$; plastic limit, 17.4\%; liquid limit, 28.9\%; optimum water content, $18 \%$; maximum dry unit weight, $1.77 \mathrm{~g} \mathrm{~cm}^{-3}$; plasticity index, 11.5. Moreover, the particle size distribution is presented in Figure 2. As per the Chinese Soil Classification System, the soil was classified as silty clay.

CLPs are cross-linked copolymers synthesized by grafting PAM with $\mathrm{CMC}$, and the preparation reaction formula is shown in Figure 3A. First, $10 \mathrm{~g}$ of CMC and $1 \mathrm{~g}$ of PAM were added to 200 and $100 \mathrm{ml}$ of ultrapure water, respectively. Then, the two solutions were heated in a water bath at $80^{\circ} \mathrm{C}$. Next, we added $40 \mathrm{ml}$ of CMC solution, $10 \mathrm{ml}$ of PAM solution, and $50 \mathrm{ml}$ of distilled water to the flask and used ammonium persulfate as the initiator for graft copolymerization. To ensure the full progress of the cross-linking reaction, the solution was stirred for $2 \mathrm{~h}$ to obtain CLPs. The FTIR spectrum of the CLPs is shown in Figure 3B. There were numerous absorption peaks in the 

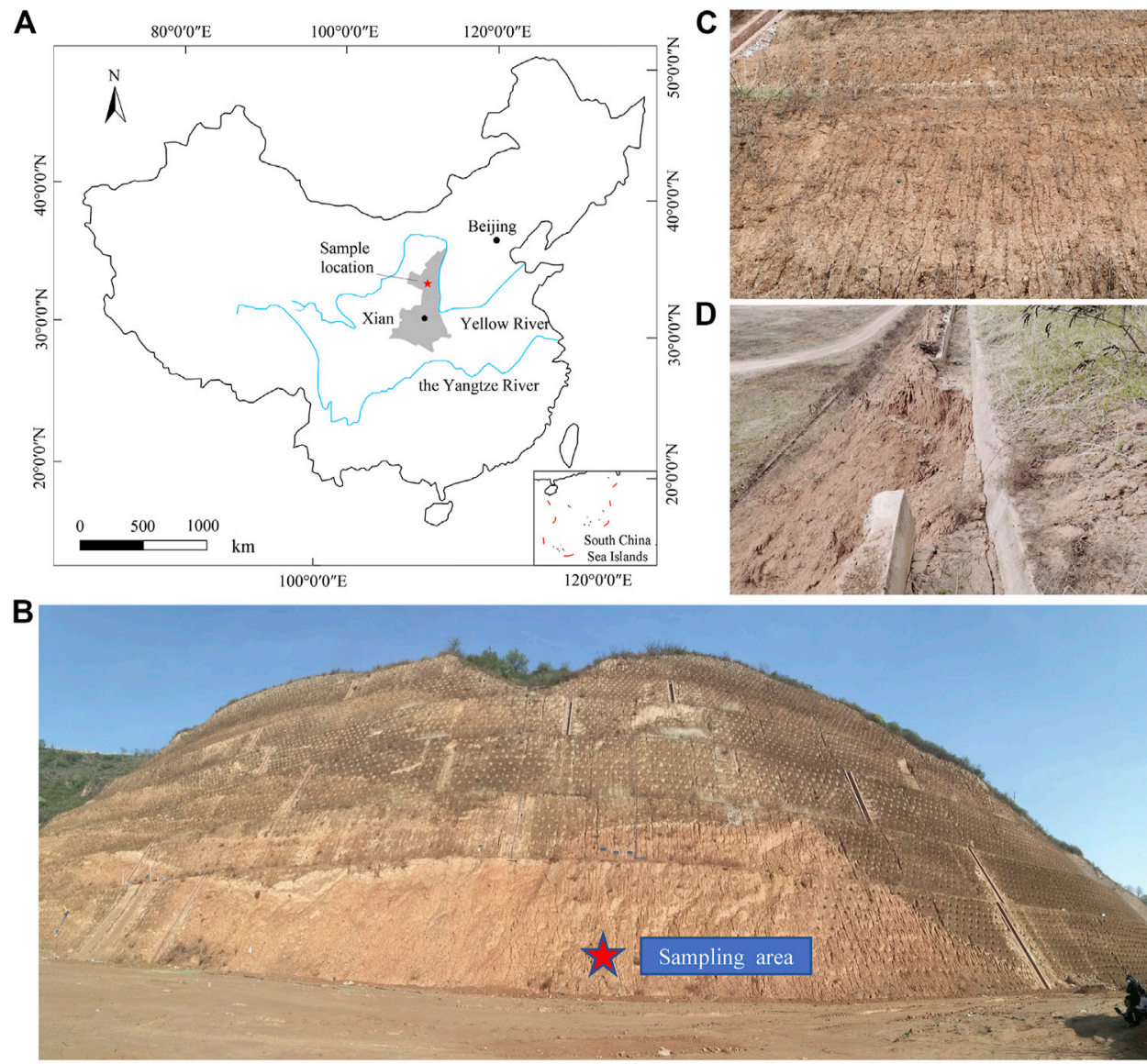

FIGURE 1 | Soil erosion on loess hillslope and sample location. (A) Geographical location of the sampling area; (B) panoramic image of the sampling area; (C) erosion gully on the hillslope; (D) drain collapsed owing to water erosion.

CLPs, including $\mathrm{OH}$ stretching vibration $\left(3,400 \mathrm{~cm}^{-1}\right), \mathrm{CH}_{2}$ asymmetric stretching vibration $\left(2,945 \mathrm{~cm}^{-1}\right),-\mathrm{CH}_{2^{-}}$bending vibration $\left(1,459 \mathrm{~cm}^{-1}\right), \mathrm{C}=\mathrm{O}$ stretching vibration $\left(1,735 \mathrm{~cm}^{-1}\right)$, $\mathrm{O}-\mathrm{C}-\mathrm{C}$ antisymmetric stretching vibration $\left(1,272 \mathrm{~cm}^{-1}\right)$, symmetrical CO deformation $\left(1,146 \mathrm{~cm}^{-1}\right)$, and aromatic ring $\mathrm{CH}$ twisting vibration $\left(669 \mathrm{~cm}^{-1}\right)$. All absorption peaks at these positions are caused by the characteristic functional groups in CMC and PAM. The CLPs are in the form of a transparent amorphous liquid, and their basic parameters were: concentration, 2.0\%; $\mathrm{pH}$ 6.8-7.2; viscosity, $25 \mathrm{~m} \mathrm{~Pa} \mathrm{~s}$; density, $1.1 \mathrm{~g} \mathrm{~cm}^{-3}$; boiling point, $100^{\circ} \mathrm{C}$.

\subsection{Sample Preparation}

The collected loess was dried and sieved through a 2-mm sieve. Then, the CLPs were diluted to $0 \%$ (water), $0.4,0.8,1.2,1.6$, and $2.0 \%$ (undiluted). We took the diluent of $18 \%$ of the dry weight of loess and stirred it to obtain the stable loess of CLPs. Stable loess with different CLPs concentrations was obtained by adjusting the concentration of CLPs solution. According to the dry density of $1.5 \mathrm{~g} \mathrm{~cm}^{-3}$ (85\% of the maximum dry density), layering and compaction in the standard sample preparation mold were carried out so that the sample was uniform. The UCS mold was a cylinder with a diameter of $50 \mathrm{~mm}$ and a height of $100 \mathrm{~mm}$.
The SWCC mold was a ring cutter with a diameter of $61.8 \mathrm{~mm}$ and a height of $20 \mathrm{~mm}$. The disintegration test mold was a cylinder with a diameter of $61.8 \mathrm{~mm}$ and a height of $40 \mathrm{~mm}$. Following the unconfined compressive test, the samples were required for SEM. The UCS samples were demolded for testing after curing for $3,7,14$, and 28 days. Other samples were demolded for testing after curing for 14 days.

\subsection{Test Methods}

\subsubsection{Unconfined Compressive Strength Test}

The UCS test was carried out according to the Chinese Standard for Soil Test Method (GB/T 50,123, 2019) using strain-controlled unconfined compression apparatus (YYW-2, Ningxi Soil Instrument Co., Ltd, China) at a loading rate of $2.4 \mathrm{~mm} / \mathrm{min}$. The relationship curve between axial stress $(\sigma)$ and axial strain $(\varepsilon)$ was drawn, and the peak stress $(\sigma f)$ on the curve was taken as the UCS. When the peak stress on the curve was not evident, the axial stress corresponding to $15 \%$ of the axial strain was taken as the UCS.

\subsubsection{Disintegration Test}

The disintegration test was carried out by the static water measure method. Into a beaker, we placed $1,500 \mathrm{ml}$ of water and the prepared disintegration sample $m_{0}$. The state of the sample was recorded at 


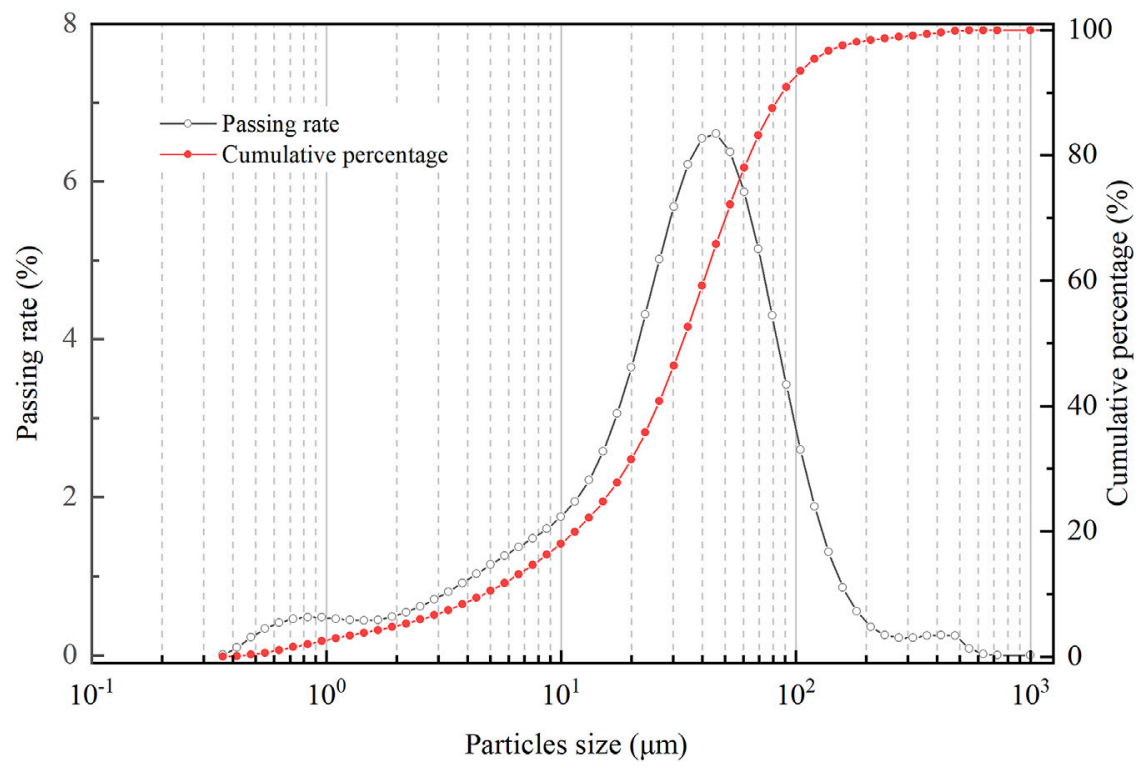

FIGURE 2 | Particle-size distribution curves of loess.

$2 \mathrm{~s}, 10 \mathrm{~s}, 1,10,60 \mathrm{~min}$, and $24 \mathrm{~h}$. After $24 \mathrm{~h}$, the beaker was placed for $12 \mathrm{~h}$ to precipitate the residual samples, absorb the supernatant, and air dry to obtain the sample. Then, the samples were cooled to $25^{\circ} \mathrm{C}$ for sieving, the soil mass in each particle size range was recorded, and the stability index was calculated using Eq. 1 (Zhang et al., 2020).

$$
\boldsymbol{K}=\frac{\sum_{n=1}^{11}\left[10 \boldsymbol{m}_{\boldsymbol{n}} \times(\boldsymbol{n}-1)\right]}{\boldsymbol{m}_{0}}
$$

where $K$ is the stability index with a value of $0-100$; the range of $n$ is 1-11; and $m_{n}$ corresponds to sieved particle sizes of $0-1,1-2$, $2-5,5-10,10-20,20-30,30-40,40-50,50-60,60-61.8$, and $61.8 \mathrm{~mm}$ (initial size).

\subsubsection{Soil-Water Characteristic Curve Test}

The SWCC test was carried out with a 1D-SDSWCC pressure plate extractor (Earth Products China Ltd, China). The dehumidification curve was used to characterize the SWCC. The sample was fully saturated before the test and then placed on a porous ceramic plate for testing. The suction range of the instrument was $1-1,500 \mathrm{kPa}$. The suction of the matrix was loaded by the "axis translation technique". The reference of negative pore water pressure was translated from the standard atmospheric pressure to the final pressure of the loading chamber. By increasing the pore gas pressure, matrix suction was applied to the sample to force the soil water to seep out, and the drainage volume of the soil was measured to obtain the matrix suction-volume water content relationship curve. Since the dehydration process of cohesive soil is relatively slow, loess treated with $1.6 \%$ CLPs and untreated loess were selected for the experiment.

The van Genuchten model (van Genuchten, 1980) was used to obtain the air entry value, dehumidification rate, residual water content, and other parameters of treated and untreated loess. The formula is as follows:

$$
\boldsymbol{\theta}_{w}=\boldsymbol{\theta}_{r}+\frac{\left(\boldsymbol{\theta}_{s}-\boldsymbol{\theta}_{r}\right)}{\left[1+(\boldsymbol{a} \times \boldsymbol{\varphi})^{n}\right]\left(1-\frac{1}{n}\right)}
$$

where $\theta_{w}$ is the volumetric water content; $\theta_{s}$ and $\theta_{r}$ are the saturated and residual volumetric water content (\%), respectively; $\varphi$ is the matrix suction $(\mathrm{kPa}) ; a$ is the air entry value $(\mathrm{kPa})$; and $n$ is affected by soil pore characteristics, which is a parameter related to the dehydration rate of the soil for high air entry values.

\subsubsection{Pot Experiment}

To explore the effect of CLPs on plant growth, a pot experiment was conducted. The experimental subjects comprised one control (CLP concentration of 0\%) and three CLP treatment groups (CLP concentration of $0.8,1.6$, or $2.0 \%)$. Alfalfa was selected for the experiments as this plant was often used for slope protection and cultivation in loess areas. We placed $4 \mathrm{~kg}$ of loess soil in 12 pots (three treatments plus the control with three replicates) of $24 \mathrm{~cm}$ diameter and $20 \mathrm{~cm}$ height, and then sowed 100 selected seeds into each pot. Each pot was sown with 100-selected seeds, covered with approximately $1 \mathrm{~cm}$ of soil, covered with plastic wrap, and placed in a greenhouse for cultivation. The indoor cultivation temperature, relative humidity, and light period were controlled at $25^{\circ} \mathrm{C}, 60 \%$, and $16 \mathrm{~h}$, respectively. Once the plants had developed three-petaled leaves, the germination rate of alfalfa was calculated. In order to ensure sufficient space and nutrients in the pot, 50 seedlings were selected. Control the same number of seedlings to confirm that the difference in soil water content and plant growth is not caused by the inconsistent number of seedlings. Five hundred milliliters of pure water was supplied every 2 days. In the first 4 weeks after germination, alfalfa plant height was measured weekly. Meanwhile, to study the health of 

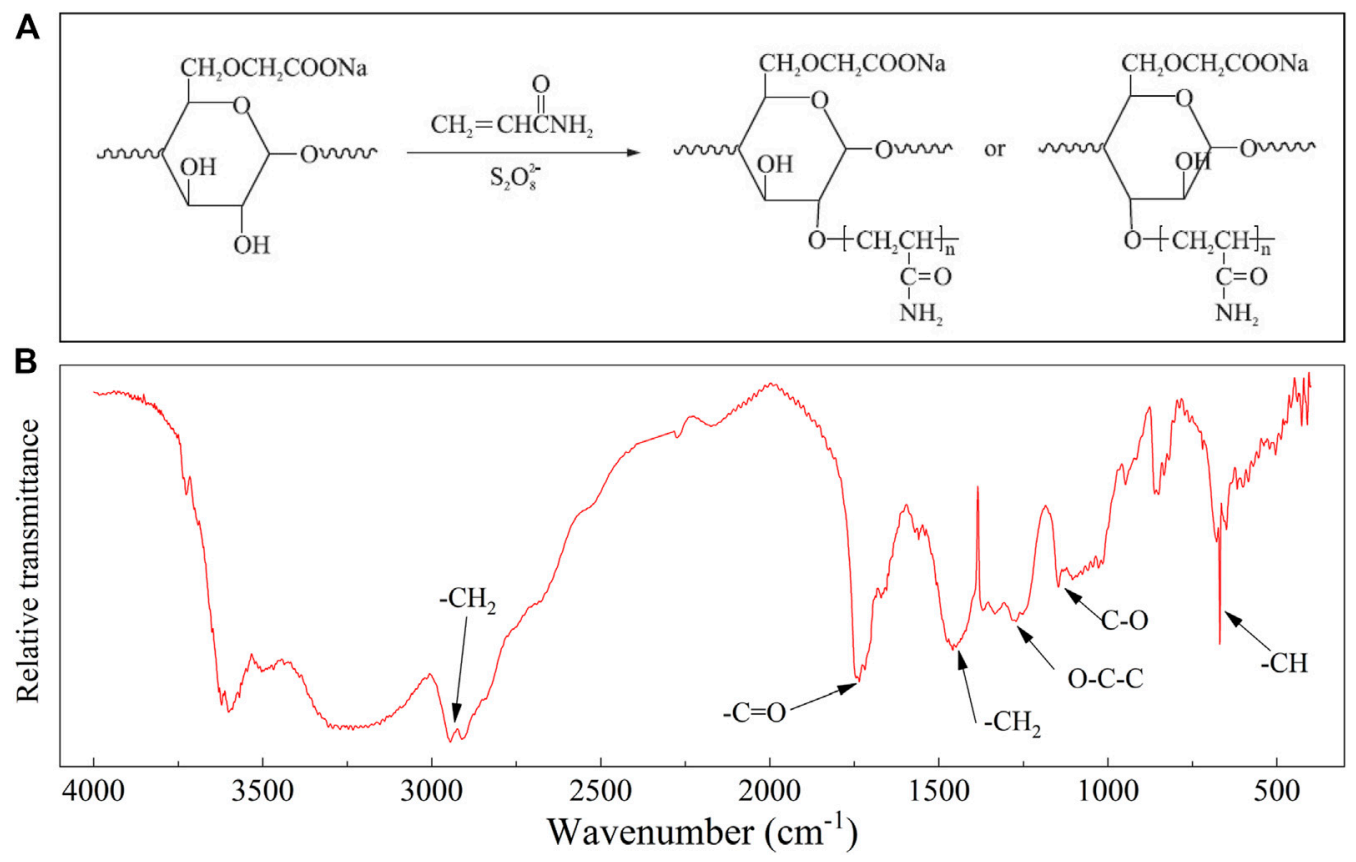

FIGURE 3 | (A) Reaction formula for preparing cross-linked polymers (CLPS); (B) Fourier-transform infrared reflection spectrogram of CLPS.

the plants under adverse conditions, the water content of potted plants in each group was controlled to be the same. Then, the humidifier was turned off and watering was stopped. The drought stress treatment was carried out to the sixth week for measuring soil water content. After rehydration, we continued to monitor the plant height indicator after 8, 10, and 12 weeks.

\subsubsection{Scanning Electron Microscopy Test}

The microstructure of soil treated with CLPs at different concentrations was analyzed by scanning electron microscopy SEM. A Prisma E scanning electron microscope (Thermo Fisher Scientific, Waltham, Massachusetts, United States) was used. The samples were plated with a thin layer of gold before testing to avoid the accumulation of electric charges on the surface of the samples. Using image processing techniques, we vectorized the SEM images of soil microstructure, and the pore structure characteristics were quantitatively analyzed. The process included 1) preprocessing, 2) binarization, 3) rasterization, 4) vectorization, 5) measuring the perimeter and area, and 6) calculating the surface void ratio according to the following formula.

$$
e_{m}=S_{n} /\left(S-S_{n}\right) \times 100 \%
$$

where $\boldsymbol{e}_{\boldsymbol{m}}$ is the surface void ratio (the ratio of the pore area to the area of the soil particles in the two-dimensional image); and $\boldsymbol{S}_{\boldsymbol{n}}$ and $S$ are the total areas of the pore polygons in the image and the total area of the image in the same statistical range, respectively.

\subsubsection{Field Test}

Through the field test, the role of CLPs in the prevention and control of loess hillslope erosion was evaluated. The loess sampling site was an engineering excavation hillslope with a slope of $50-55^{\circ}$. Two test plots ( $13 \mathrm{~m}$ long; $5 \mathrm{~m}$ wide) were established. Both slopes were sown, and the selected grass species were alfalfa, tall fescue, ryegrass, and bluegrass. The CLP diluent, loess, and seeds were mixed uniformly and then spread for sowing. Firstly, $15 \mathrm{~kg}$ of $1.6 \%$ CLPs was added to every $100 \mathrm{~kg}$ of loess on the treated slope surface, and the same amount of water was added to the untreated slope surface. Then, $50 \mathrm{~g}$ of mixed grass seeds was added. After being evenly combined, the mixture was sprayed on the slope. The field test procedures were as follows: 1) The vegetation and topsoil were removed, and the slope surface was leveled by compaction. 2) Three-dimensional nets were laid on the modified slope and fixed with pegs. 3) The loess, seeds, and CLP diluent (or pure water for the untreated slope) were mixed according to the above proportions and then evenly spread on the slope $(90 \mathrm{~kg}$ mixed mud per square meter was paved with a thickness of $5 \mathrm{~cm}$ ). 4) The plastic film was removed 2 weeks later, and the plots were watered every 3 days after curing. Finally, the erosional features on the slopes were observed and compared.

\section{RESULTS}

\subsection{Effect of CLPs on Unconfined Compressive Strength}

Figure 4A-D shows the stress-strain relationship of samples with different CLP concentrations for each curing period. Compared with the untreated samples, the $\sigma_{\mathrm{f}}$ of the treated samples notably increased, while Figures 4E,F shows the change trend in the UCS of samples treated with different 

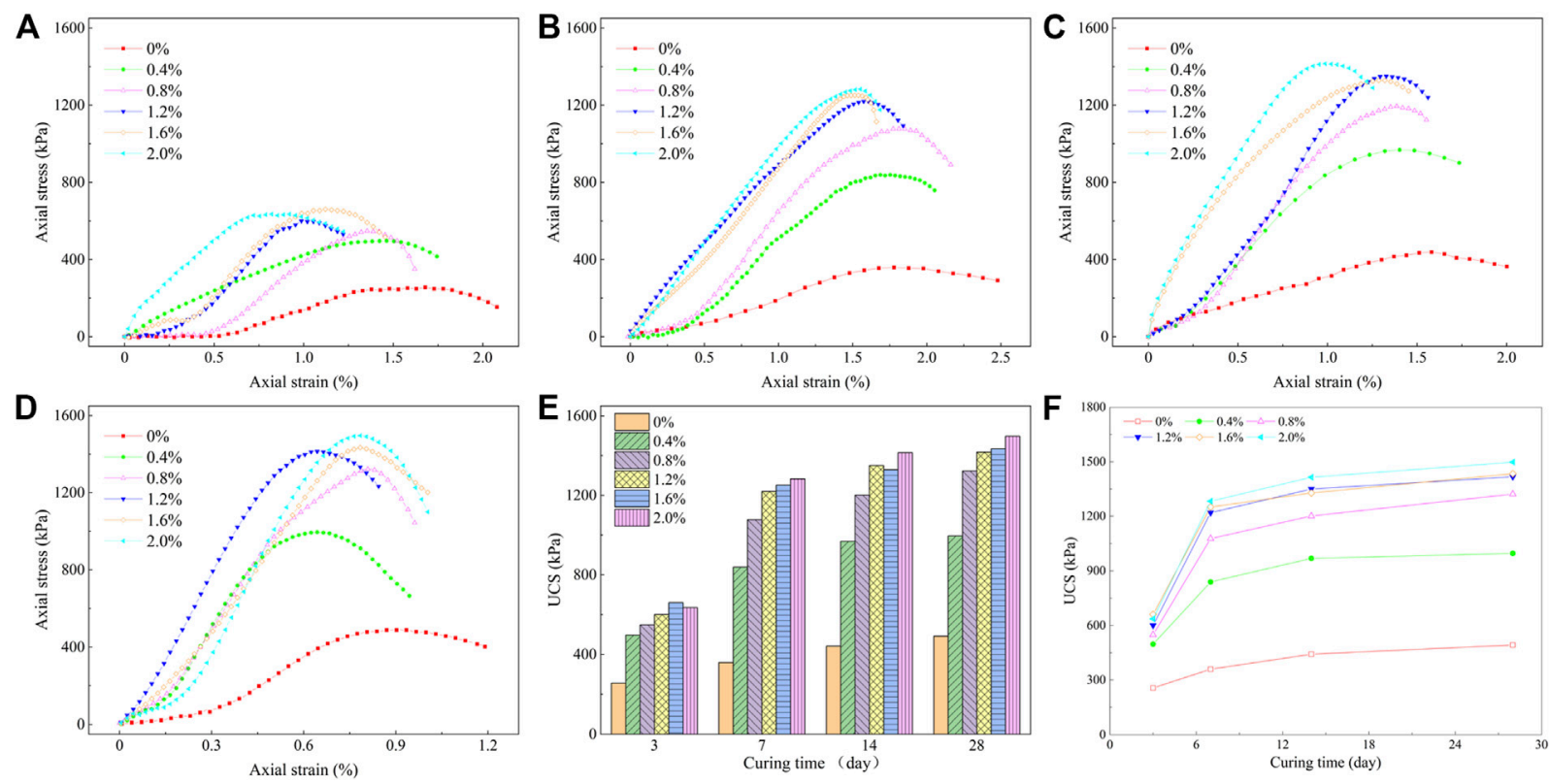

FIGURE 4 | (A-D) Stress-strain curves of cross-linked polymer-treated loess curing for 3, 7, 14, and 28 days (E-F) Unconfined compressive strength of crosslinked polymer-treated loess at different curing times.

concentrations of CLP with curing time. The $\sigma_{\mathrm{f}}$ of the CLPtreated samples was significantly higher than that of the untreated samples. As the concentration of CLP increased, the $\sigma_{\mathrm{f}}$ of the samples exhibited an increasing trend. Comparing the UCS of samples with different CLP concentrations in the same period, at 3 days, the strength slightly increased with the increase in material content, and at 7 days, the UCS of each sample showed an increasing trend with the increase in CLP concentration. After 28 days, the $\sigma_{\mathrm{f}}$ of the $2.0 \%$ CLP-treated samples was $1,497.84 \mathrm{kPa}$, which was 3.04 times that of the untreated samples $(491.97 \mathrm{kPa})$. However, with the continuous increase in CLPs, the $\sigma_{\mathrm{f}}$ of soil tended to gradually stabilize. Compared with $2.0 \%$ CLPs, the application of $1.2 \%$ CLPs increased strength by more than $90 \%$ in each curing period. Therefore, considering the cost and strength, the optimal concentration range of CLPs was $1.2-1.6 \%$.

\subsection{Effect of CLPs on Disintegration}

Table 1 and Figure 5 illustrate the disintegration of samples treated with different concentrations of CLPs after soaking for $24 \mathrm{~h}$. According to the disintegration failure mode and disintegration products, the untreated loess immediately and strongly bubbled and collapsed after being soaked in water and completely disintegrated within $1 \mathrm{~min}$ leaving scaly fragments and powder, and the water became turbid. In the loess samples reinforced with 0.4 and $0.8 \%$ CLPs, cracks appeared initially after being immersed in water and further expanded over time; the loess completely disintegrated after soaking for $10 \mathrm{~min}$. The disintegration mode was layered spalling accompanied by a massive slump, and the final disintegration product was a muddy mixture of thick scales and granular fragments. The loess samples treated with $1.2 \%$ CLPs had to be soaked for 10 min before cracks appeared and did not completely disintegrate until $1 \mathrm{~h}$. The final disintegration product was thick soil. The loess samples treated with $>1.6 \%$ CLPs remained intact. Therefore, the addition of CLPs significantly improved the anti-disintegration property of loess.

Improvements in the anti-disintegration property of loess can be quantitatively evaluated using the stability index. The stability index results of the samples treated with CLPs are shown in Figure 6. When the concentration of CLPs was $0,0.4,0.8,1.2,1.6$, and $2.0 \%$, the stability index was $0,3.85,9.57,20.28,88.06$, and 100 , respectively. When the CLP concentration was $<1.6 \%$, the anti-disintegration property sharply increased. At CLP concentration of $1.6 \%$, the stability index slowly increased, indicating increased stability in the loess. After loess samples treated with $2.0 \%$ CLPs were soaked for $24 \mathrm{~h}$, their stability index reached $100 \%$.

\subsection{Effect of CLPs on Soil Water Retention}

The relationship between the matrix suction and volumetric water content of treated and untreated loess was characterized by the SWCC (Figure 7). The SWCC of both treated and untreated loess were consistent with the VG model. However, the SWCC of the treated loess trended to the upper right compared with the untreated loess, that is, under the same matrix suction, the treated loess had a higher volumetric water content than the untreated loess. These results are in line with previous findings (Eyo et al., 2020; Zhai et al., 2020). White et al. (1970) and Vanapalli et al. (1999) suggested that the SWCC can be divided into three stages namely boundary effect, transition, and unsaturated. Combined with the fitting parameters of every stage obtained from the VG model, the hillslope of the transition 
TABLE 1 | Disintegration of loess under different cross-linked polymer (CLP) concentrations.

\section{CLP concentration}

(\%)

\begin{tabular}{llr}
\hline 0 & Bubbly & Cracked \\
0.4 & Bubbly & - \\
0.8 & Bubbly & - \\
1.2 & Bubbly & - \\
1.6 & Bubbly & - \\
2.0 & Bubbly & -
\end{tabular}

- - indicates no significant changes were observed.
Disintegration experimental phenomenon

\begin{tabular}{|c|c|c|c|c|c|}
\hline \multicolumn{6}{|c|}{ Disintegration experimental phenomenon } \\
\hline $2 \mathrm{~s}$ & $10 \mathrm{~s}$ & $1 \mathrm{~min}$ & $10 \mathrm{~min}$ & $60 \mathrm{~min}$ & $24 \mathrm{~h}$ \\
\hline Bubbly & Cracked & Disintegrated and Turbid & -- & -- & -- \\
\hline Bubbly & -- & Cracked & Disintegrated & -- & -- \\
\hline Bubbly & -- & -- & Cracked & Disintegrated & -- \\
\hline
\end{tabular}
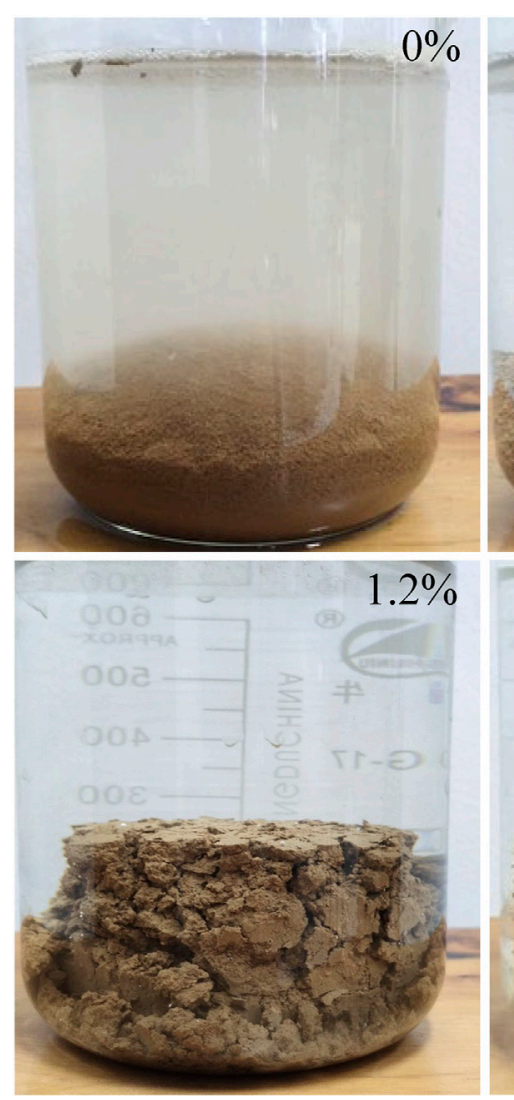
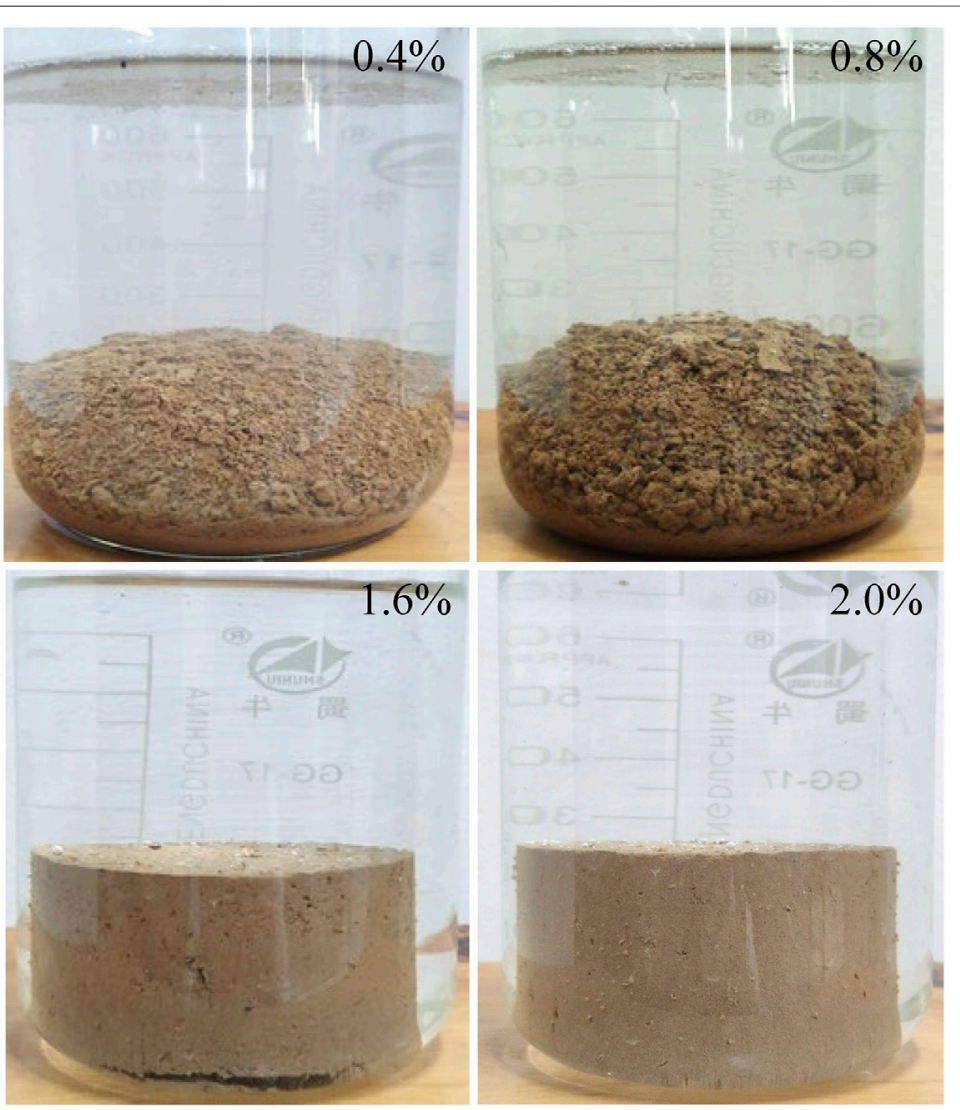

FIGURE 5 | Samples treated with different cross-linked polymer (CLP) concentrations following immersion for 24 h.

stage, saturated volumetric water content, air entry value, dehumidification rate, and residual water content of loess can be obtained (Table 2). Following this, the effect of CLPs on soil water retention was analyzed. In the boundary effect stage, the soil was saturated, and only free water driven by gravity was discharged. The saturated volumetric water content of treated loess was $54.24 \%$ and that of untreated loess was $43.25 \%$, indicating that CLPs considerably improved the saturated volumetric water content of loess. With the gradual increase in matrix suction, the capillary water in the pores was gradually discharged due to its inability to resist the applied matrix suction. The critical value of matrix suction is referred to as the air-entry value. The air-entry value of the treated loess $(6.26 \mathrm{kPa})$ exceeded that of the untreated loess $(5.16 \mathrm{kPa})$, indicating that CLPs improved the capillary water holding capacity of loess. After the matrix suction exceeded the air-entry value, the transitional stage began, during which the changes in the SWCC were even more considerable. The absolute value of the tangent slope of the transition stage is defined as the dehumidification rate, which represents the strength of the capillary force in the soil against the loss of external forces. The dehumidification rate of treated loess was 0.31 and that of untreated loess was 0.74 . This result indicated that increased matrix suction made it more difficult for the capillary water of the treated loess to discharge, thereby, strengthening the water retention capacity. The suction continued to increase and 


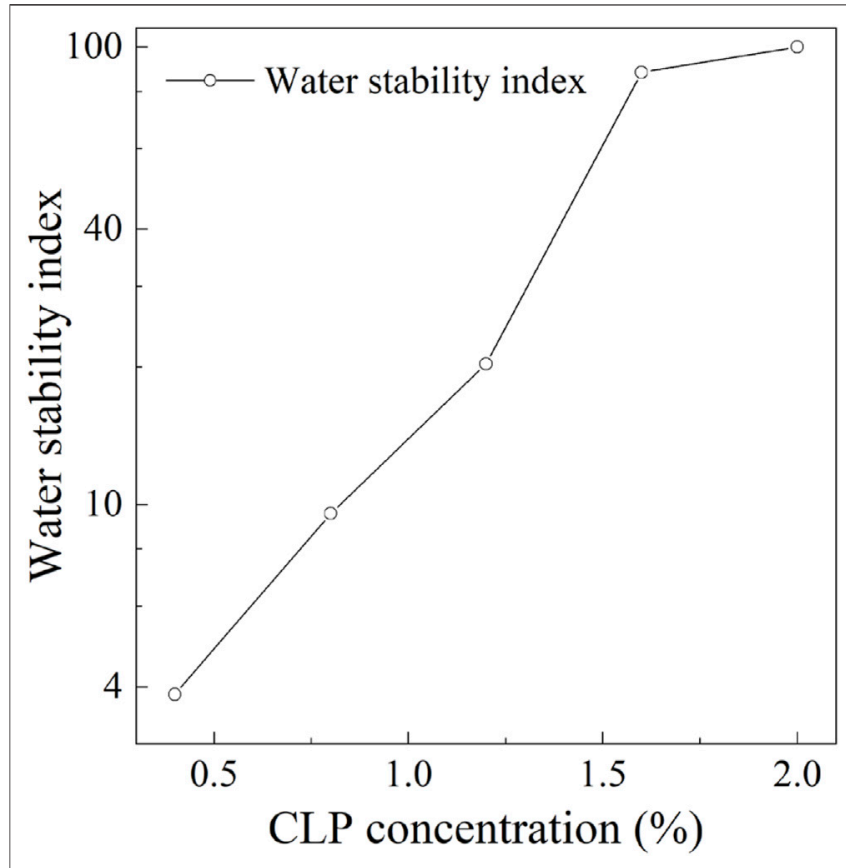

FIGURE 6 | Anti-disintegration index of samples treated with different concentrations of cross-linked polymers (CLPs).

reached the unsaturated stage. With increased suction, the water content stopped decreasing, and the residual water content of treated loess significantly increased compared with that of untreated loess. Calculating the effective water content (field water content minus residual water content) showed that the effective water content of treated loess was higher than that of untreated loess.

\subsection{Effect of CLPs on Plant Growth Characteristics}

The water content of potted loess was measured after 2 weeks of drought stress (Figure 8A). Under the same initial water content and culture conditions, the water content of potted loess treated with CLP concentrations of $0,0.8,1.6$, and $2.0 \%$ was $4.34,4.97$, 5.38 , and $5.73 \%$, respectively. This result indicated that when CLP concentration increased, the water content of the potted loess also increased. The loess with treated CLPs had an improved water retention capacity owing to the presence of hydrophilic functional groups. This, in turn, enhanced the infiltration of water into loess particles.

After sowing for 3 days, the germination rate of the seeds in each pot was calculated (Figure $\mathbf{8 A}$ ). The germination rate of untreated seeds was $65 \%$, and that of seeds treated with $0.8,1.6$, and $2.0 \%$ CLPs was 66,67 , and $69 \%$, respectively, indicating that CLPs did not adversely affect the germination rate. After 28 days, the average plant height was measured, as shown in Figures 8B,C. The plants grew well, and evident differences in plant height were observed after 3 weeks. As the concentration of CLP increased, plant height also increased, indicating that CLPs promoted plant growth to some extent. Treated loess exhibited less water evaporation, therefore, more water was available to promote plant growth. After 12 weeks, the alfalfa taproots in loess treated with $2.0 \%$ CLPs were significantly more developed and thicker than those in untreated loess. These findings suggest that the application of CLPs did not inhibit plant development and

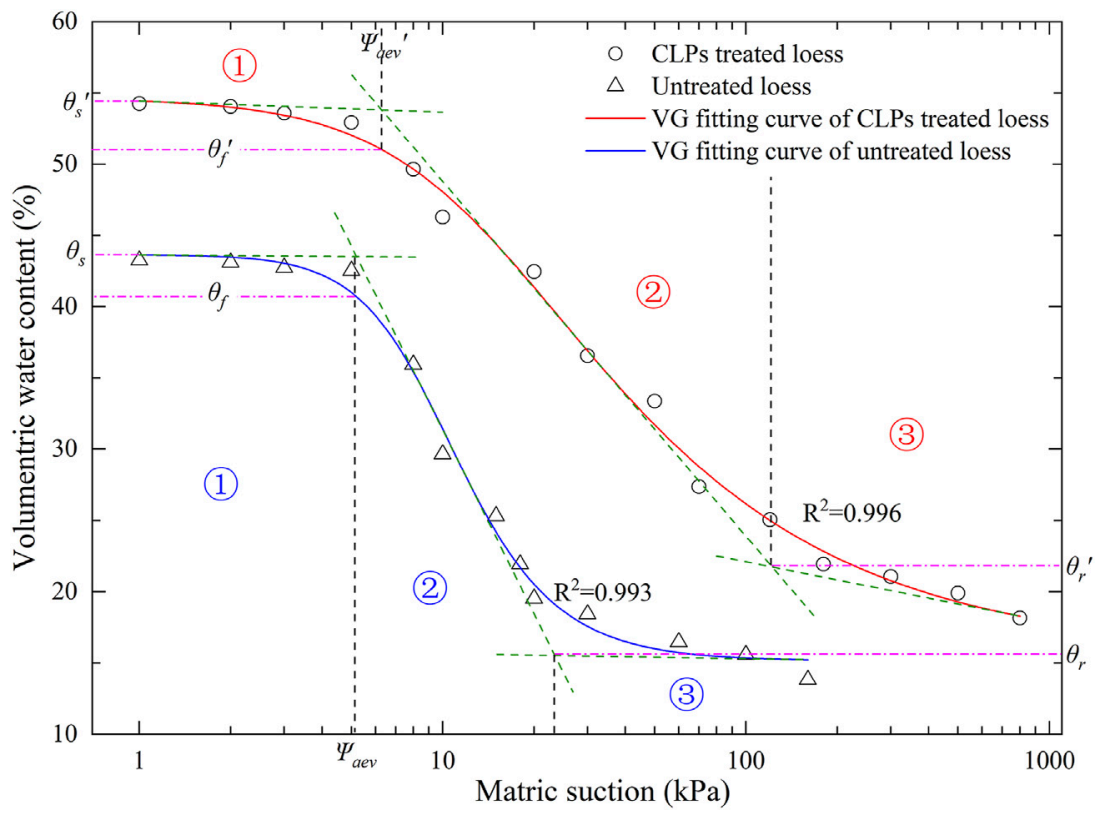

FIGURE 7 | Soil-water characteristic curve of treated and untreated loess. Regions (1), (2), and (3) represent the boundary (gravity water loss area), transition (capillary water loss area), and residual (combined water loss area) stages, respectively (White et al., 1970; Vanapalli et al., 1999). 
TABLE 2 | Soil-water characteristic parameters of treated and untreated loess.

\begin{tabular}{|c|c|c|c|c|c|c|}
\hline $\begin{array}{l}\text { CLP concentration } \\
(\%)\end{array}$ & $\begin{array}{l}\text { Saturated water } \\
\text { content (\%) }\end{array}$ & $\begin{array}{l}\text { Field capacity } \\
(\%)\end{array}$ & $\begin{array}{l}\text { Entry air value } \\
\text { (kPa) }\end{array}$ & $\begin{array}{l}\text { Dehumidification rate } \\
\text { (\%) }\end{array}$ & $\begin{array}{l}\text { Residual water } \\
\text { content }(\%)\end{array}$ & $\begin{array}{c}\text { Effective water } \\
\text { content (\%) }\end{array}$ \\
\hline 0 & 43.25 & 40.76 & 5.16 & 0.31 & 15.54 & 25.33 \\
\hline 1.6 & 54.24 & 51.02 & 6.26 & 0.74 & 21.74 & 29.32 \\
\hline
\end{tabular}
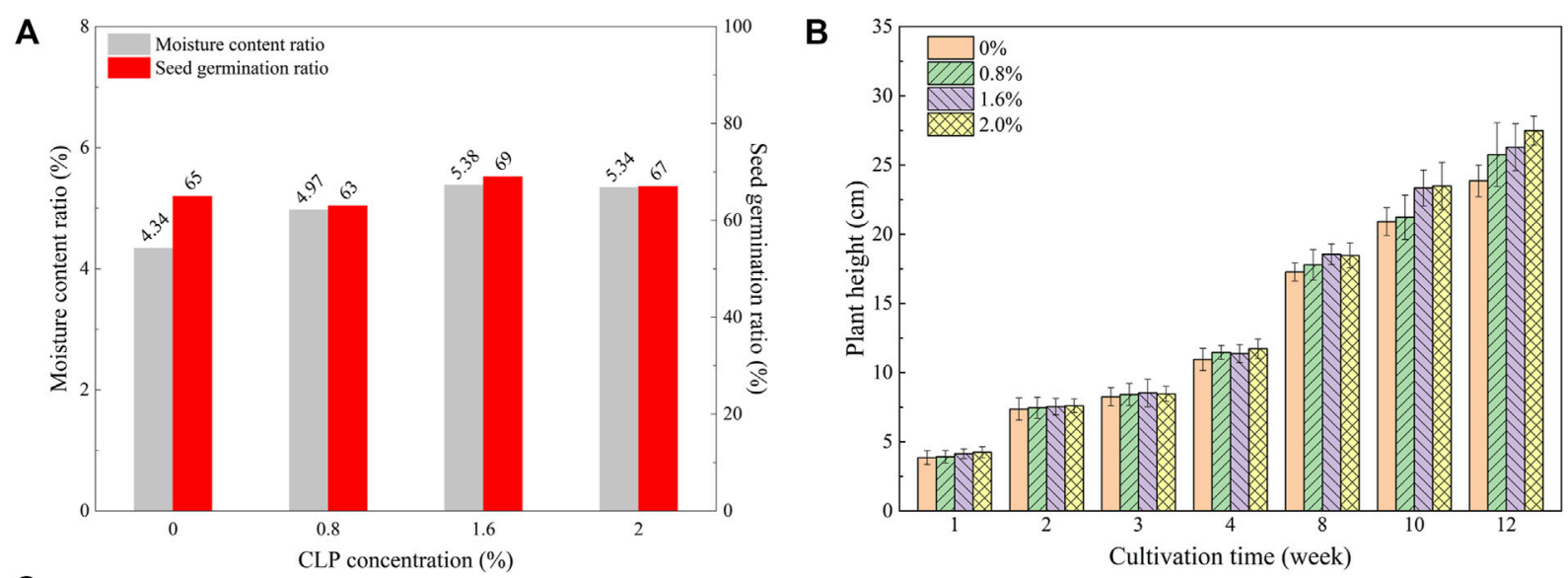

C
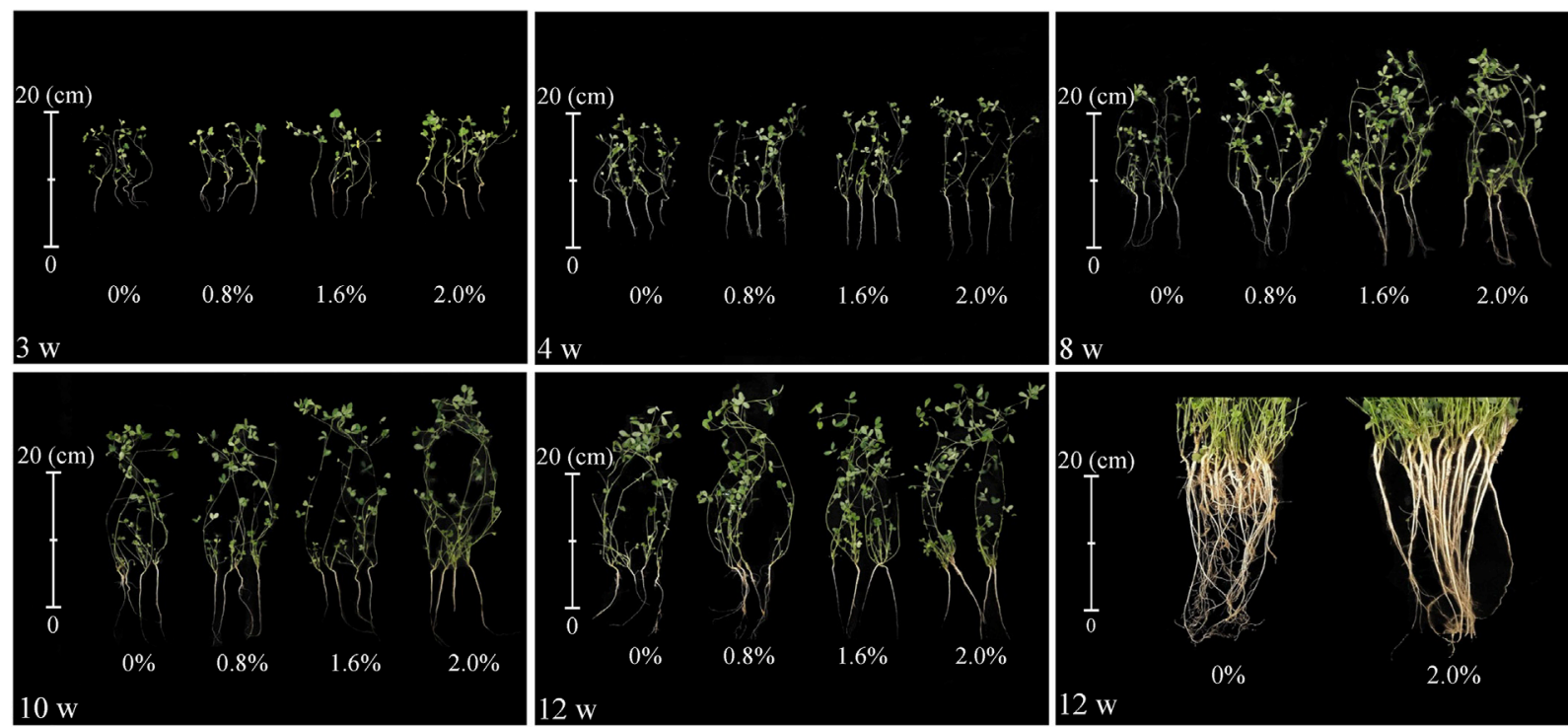

FIGURE 8 | (A) Water content ratio of potted loess treated with different cross-linked polymer (CLP) concentrations after drought stress, and its seed germination ratio 3 days after sowing. (B) Plant height of potted plants treated with different cross-linked polymer concentrations over time. (C) Potted plants treated with different cross-linked polymer (CLP) concentrations over time.

actually promoted plant growth. Therefore, CLPs can be combined with vegetation to better control loess slope erosion.

\subsection{Effect of CLPs on Soil Microstructure \\ 3.5.1 Particle Skeleton Structure}

The scanning electron micrographs (1,000× magnification) of the untreated and treated loess are shown in Figure 9A. The boundaries between the different sized particles and small debris of untreated loess can be observed in Figure 9A (0\%).
The loess particles were mainly in point contact, and intergranular pores were developed. Furthermore, the structure of the loess particles was loose and easily destroyed. This was not the case for the treated loess (Figure 9A). After the CLPs were added, they adsorbed small soil particles and connected and wrapped large particles. The boundary of the particles was blurred, and the contact mode was mainly that of inlaid contacts. The contact area between the particles increased, changing from point contact to surface contact. 

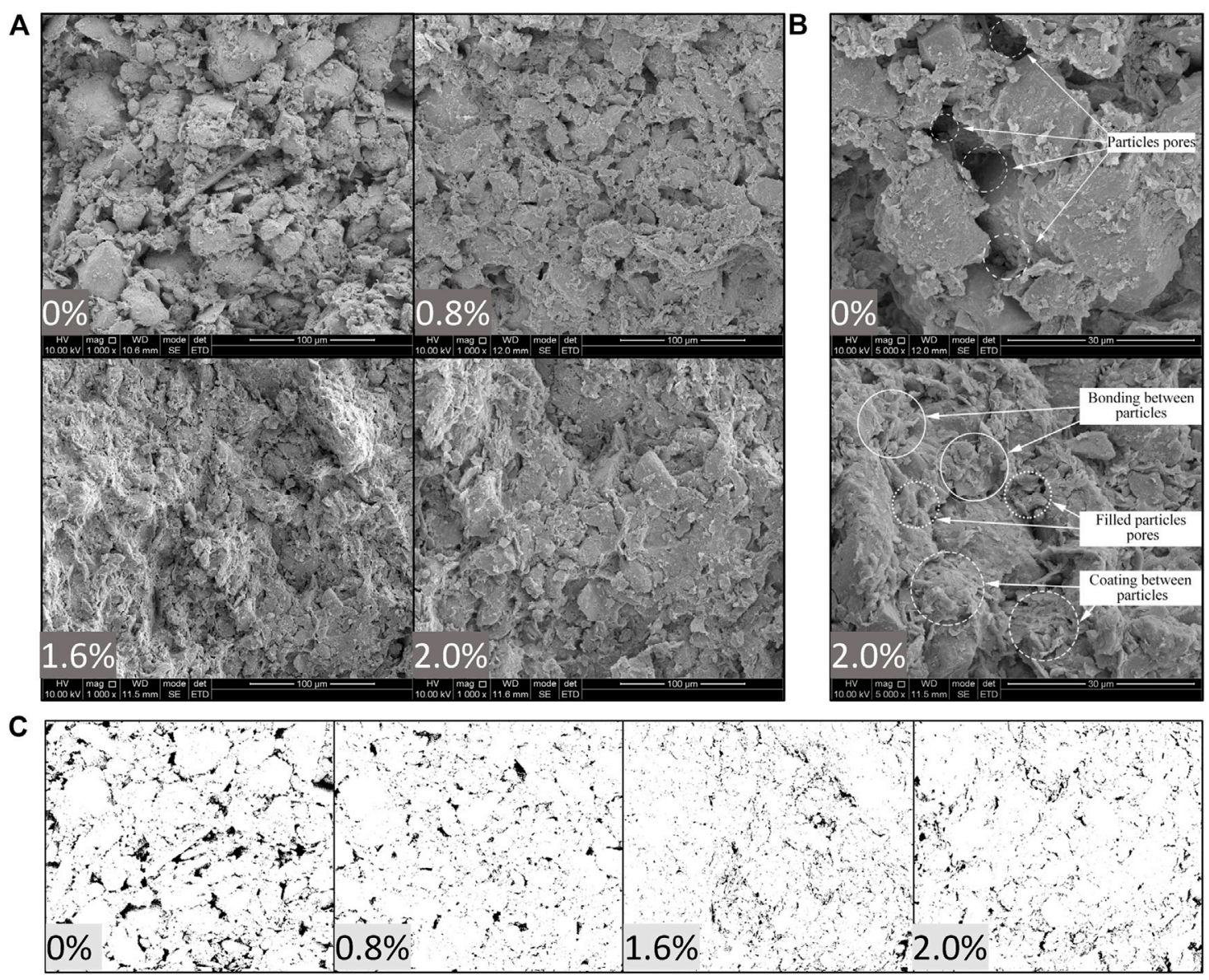

FIGURE 9 | Scanning electron micrographs of untreated and cross-linked polymer (CLP)-treated loess samples after 28 days curing at 1,000× magnification: (A) untreated loess; (B) 0.8\% CLP-treated loess; (C) 1.6\% CLP-treated loess; and (D) 2.0\% CLP-treated loess. And 5,000× magnification: (E) untreated loess; and (F) 2.0\% CLP-treated loess after curing for 28 days.

The magnification was further increased to 5,000× (Figure 9B). The untreated soil had clear particle boundaries, smooth surfaces, and evident interparticle pores. Following CLP addition, the pores were significantly reduced, and the structure was more compact. The soil particles were wrapped layer by layer by a flocculent or flaky substance, blurring the particle boundaries. One part of the CLPs was combined with particle debris and filled the large pores, while the other part was wrapped on the surface of soil particles and adhered to particle debris. Through these two actions, more soil particles were bonded to form larger aggregates, leading to increased compaction of the soil structure and further improving the structural stability.

\subsubsection{Pore Structure Analysis}

The binarized scanning electron micrographs is shown in Figure 9C. The pore data were classified according to Lei (1988) and Zhang L. et al. (2020), as shown in Table 3. The cumulative distribution curve showed that the pore diameter decreased with increasing CLP concentration (Figure 10A). The number and total area of various pores in treated loess were measured (Figures 10B,C). The treated and untreated loess had a similar number of pores, and both were dominated by small pores with few large and medium pores. As the CLP concentration increased, the number of micropores first decreased and then increased. The number of small pores remained basically unchanged, whereas the number of large and medium pores exhibited a downward trend. The total pore area of untreated loess mainly comprised large and medium pores, whereas the treated loess mainly comprised medium and small pores. With the increased CLP concentration, the total area of small pores showed little change, whereas the total area of large and medium pores significantly decreased. This result indicated that the CLPs changed the soil structure mainly by affecting the area of large and medium pores. The stabilizer wrapped the soil particles and filled the pores; therefore, the total pore area and total porosity were significantly reduced.

\section{DISCUSSION}

\subsection{Stabilization Mechanism of Solidified Loess}

The mechanisms underlaying soil stabilization vary and can be divided into physical, chemical, and biological processes. Physical 
TABLE 3 | Number of pores and surface porosity of treated loess with different cross-linked polymer (CLP) concentrations.

\begin{tabular}{|c|c|c|c|c|c|}
\hline $\begin{array}{l}\text { Pore type } \\
\text { CLP concentration } \\
(\%)\end{array}$ & $\begin{array}{l}\text { Macropore } \\
\mathrm{D} \geq 32 \mu \mathrm{m}\end{array}$ & $\begin{array}{c}\text { Mesopore } \\
8 \mu \mathrm{m} \leq \mathrm{D}<32 \mu \mathrm{m}\end{array}$ & $\begin{array}{l}\text { Small pore } \\
2 \mu \mathrm{m} \leq \\
D<8 \mu \mathrm{m}\end{array}$ & Micropore D < $2 \mu \mathrm{m}$ & $\begin{array}{c}\text { Surface porosity } \\
\text { ratio (\%) }\end{array}$ \\
\hline 0 & 20 & 168 & 769 & 2,353 & 19.09 \\
\hline 0.8 & 5 & 112 & 549 & 1,554 & 7.60 \\
\hline 1.6 & 0 & 126 & 644 & 1,542 & 6.88 \\
\hline 2.0 & 2 & 77 & 747 & 2092 & 5.22 \\
\hline
\end{tabular}

$D$ indicates the diameter.
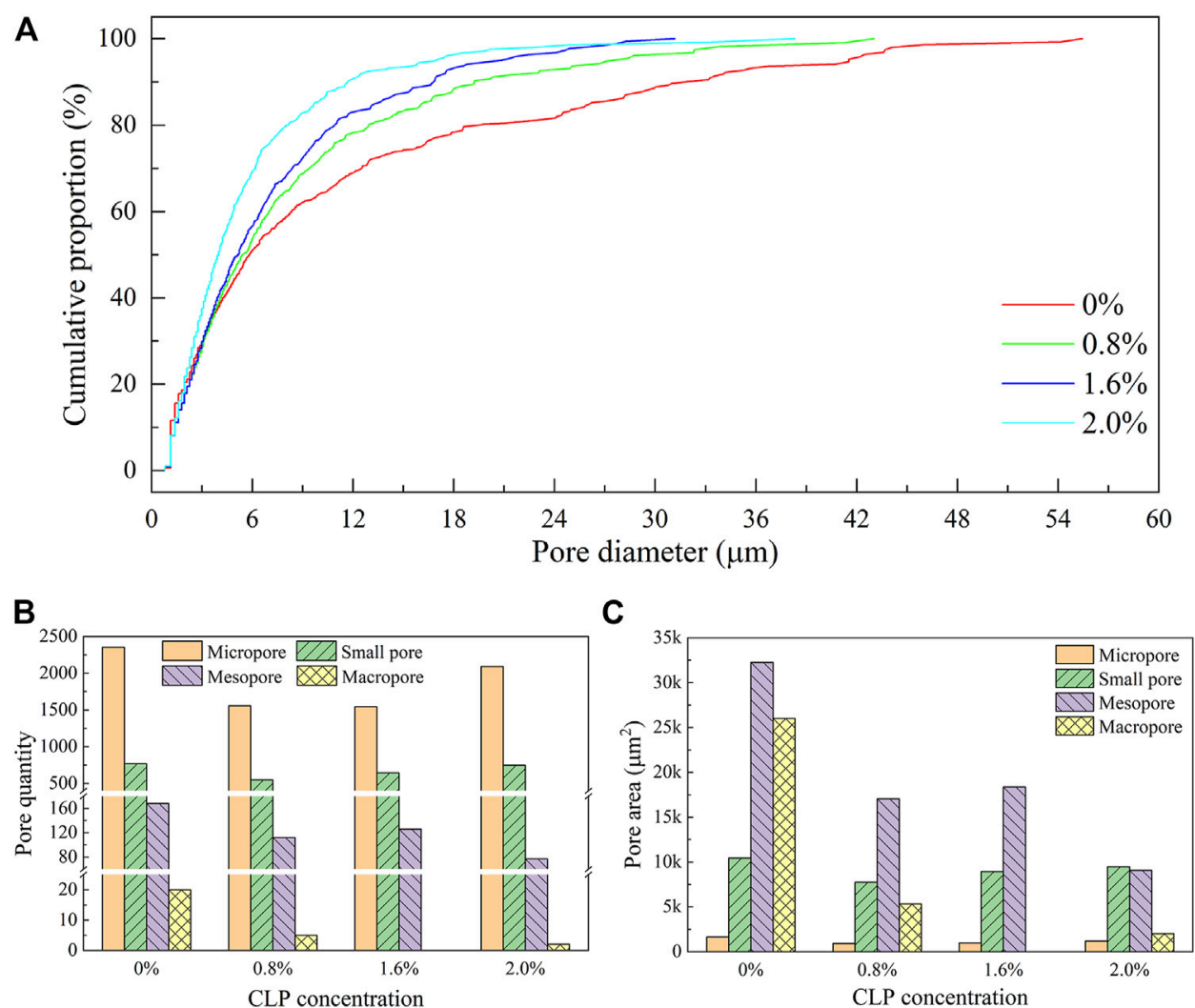

FIGURE 10 | (A) Cumulative pore distribution percentage of loess treated with different cross-linked polymer concentrations. Pore quantity (B) and total area (C) of loess treated different cross-linked polymer (CLP) concentrations.

processes include fiber reinforcement (Chebbi et al., 2020), filling, bonding, and wrapping (Ghasemzadeh and Modiri, 2020). Chemical processes include calcification, chemical bonding, hydrogen bonding, and ion exchange (Tingle et al., 2007; Dehghan et al., 2019; Zhang et al., 2019). Biological processes include microbially induced calcium carbonate precipitation (Wang et al., 2019) and enzyme-catalyzed reactions (Chandler et al., 2017). CLPs are formed by cross-linking carboxymethyl cellulose and polyacrylamide.

Traditional soil stabilizers, such as lime, cement, and fly ash, generate hydrated calcium silicate, calcium carbonate, and other products through calcification reactions, which cause evident changes in mineral composition (Choobbasti and Kutanaei, 2017; Al-mashhadani et al., 2018; James, 2020). Conversely,
CLPs are formed through polymer cross-linking and lack a calcium source for the calcification reaction. Thus, their stabilization mechanism differs from that of calcium-based stabilizers. This was demonstrated by the XRD results of different CLPs used to stabilize loess (Figure 11A). Before and after enhancement, the peak group, position, and intensity of the diffraction pattern were basically the same. This result indicated that CLPs differed from calcium-based stabilizers and did not produce new compounds that affected soil crystallization. These findings are consistent with those of Liu et al. (2020) and Zhang et al. (2016). CLPs contain hydrophilic functional groups, such as $-\mathrm{OH},-\mathrm{COOH}$, and $-\mathrm{NH}_{2}$, leading to changes in the functional groups of treated loess. According to the infrared spectra of treated loess (Figure 11B), the asymmetric stretching vibration of 

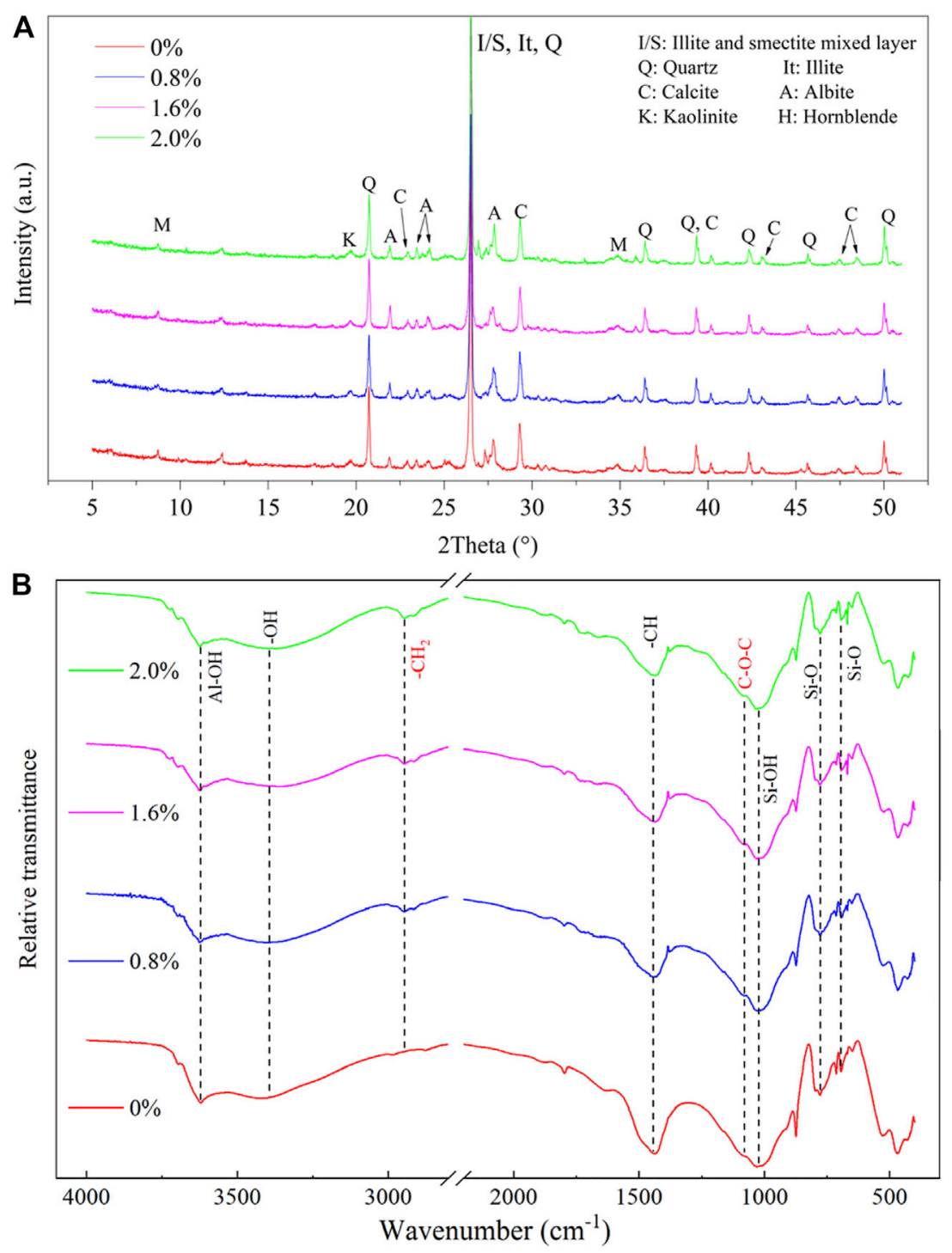

FIGURE 11 | (A) X-ray diffraction patterns of loess treated with different cross-linked polymer concentrations. (B) Fourier-transform infrared reflection spectrogram of loess treated with different cross-linked polymer concentrations.

$-\mathrm{CH}_{2}$ - was added at $2,945 \mathrm{~cm}^{-1}$. This indicated that aliphatic hydrocarbon methylene groups were added to the treated loess, corresponding to the macromolecular backbone of CLPs. Simultaneously, the $\mathrm{C}-\mathrm{O}$ symmetrical deformation peak at $1,125 \mathrm{~cm}^{-1}$ of the treated loess was more prominent, indicating the addition of an ether bond. These new functional groups were also found in the infrared spectra of the corresponding CLPs. This result indicated that CLPs were not completely hydrolyzed after being introduced into loess, and they still existed as long chains of macromolecules.

Based on our and previous results, the CLP stabilization mechanism could be described as the superposition of physical and chemical effects. The process included the following steps: 1) After the CLPs were mixed with the soil, they dissociated and released a large amount of free $\mathrm{H}+$, which was exchanged with the metal cations in the soil particles. In response, the thickness of the water film of the electric double layer was weakened, and the soil particles were arranged more closely, enhancing the mechanical properties. The particle structure, as observed through SEM, also supported this conclusion. Additionally, the dissociated $\mathrm{H}+$ could combine with elements such as $\mathrm{O}$ and $\mathrm{N}$ in loess minerals and organic matter to form hydrogen bonds and enhance the stability of the soil (Latifi et al., 2017). 2) After the mixed treated loess lost water, the CLPs formed a gel to fill the soil pores. The gaps between the particles adsorbed, wrapped, and bound soil particles to form an overall three-dimensional spatial network structure, which was more stable. This alteration also reduced the large and medium pores and the total pore area, which further improved the soil stability (Bu et al., 2019). When CLPs were added to the soil, the gel formed by its curing was filled with particles, altering the microstructure of the soil. Moreover, CLPs contain abundant hydrophilic groups. Combined, these factors could contribute to an increase in the bound water and 


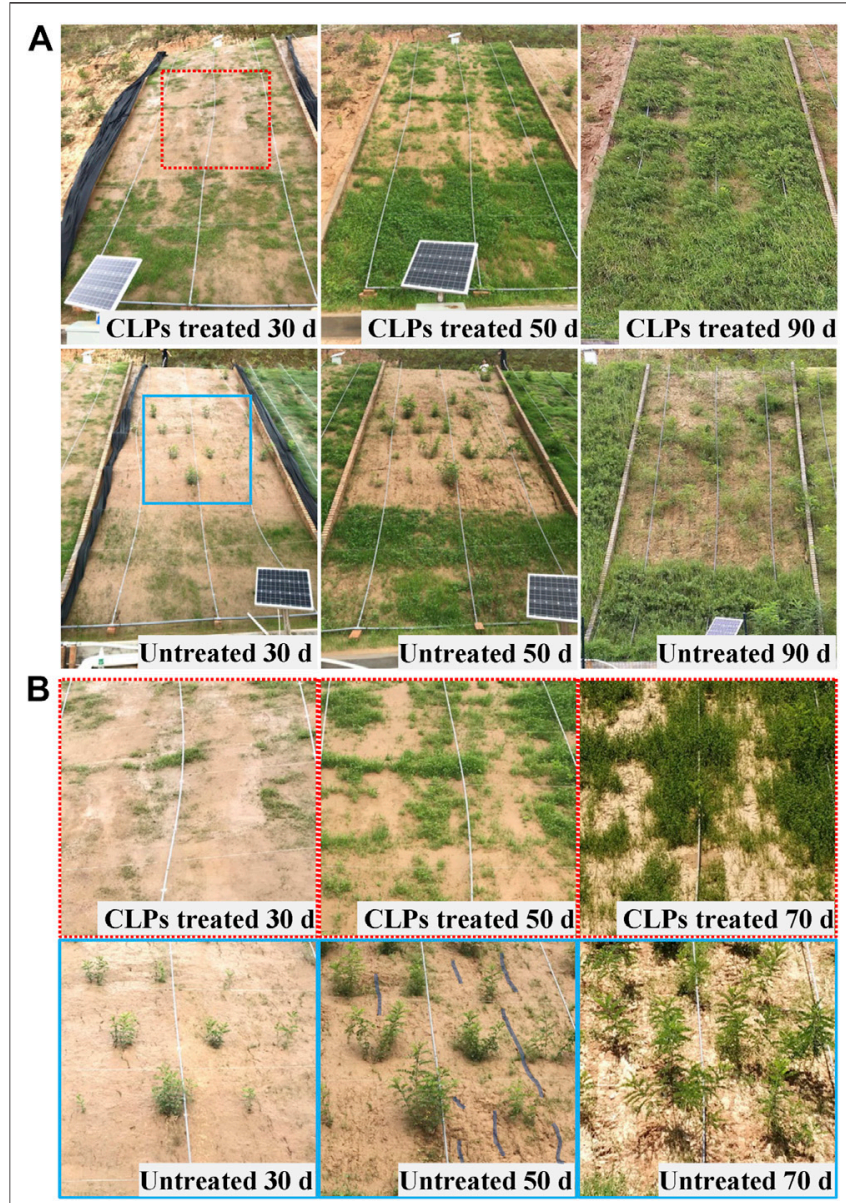

FIGURE 12 | Untreated and cross-linked polymer (CLP)-treated loess hillslopes in the field test over time. (A) Overview and (B) close-up of slopes.

capillary water content of treated loess and enhance its water retention capacity. This contribution was manifested by an increase in the effective water content and residual water content of the treated loess and a decrease in the dehumidification rate.

\subsection{Application}

Details of the slope surface in the field test are illustrated in Figure 12. Owing to the impact of rainfall erosion, some seeds were washed down, cracks appeared after 30 days, and there was more vegetation coverage in the lower part of the slope than in the upper part. This phenomenon was more evident on the untreated slope, indicating that the application of CLPs reduced soil erosion. The images after 50 days showed that increasing erosion rills appeared on the untreated slope under rainfall and irrigation conditions. However, the vegetation coverage on the treated slope significantly increased, with no significant erosion occurred. After 70 days, rill erosion further developed into flaky denudation on the untreated slope, and the surface layer peeled off, forming scaly erosion. Meanwhile, the treated loess remained basically intact. After 90 days, the untreated slope continued to deteriorate. The upper part of the untreated slope was not effectively protected by the vegetation, increasing the erosion. The worsened erosion led to vegetation deterioration, which further increased the erosion. However, the surface of the treated slope was mostly covered by vegetation forming a barrier on the surface, and the splash erosion caused by raindrops was alleviated. Therefore, the field tests showed that treating slope loess with CLPs was an effective and feasible measure for controlling soil erosion and restoring vegetation. In addition, the CLP material was used in very small quantities, achieving significant results at a concentration of only $1.6 \%$, at a cost of only 34 USD per ton soil-binder mixture.

\section{CONCLUSION}

Herein, we proposed a method for alleviating the erosion of loess slopes by stabilizing them with double cross-linked polymers. Our main conclusions are as follows:

1) CLPs can significantly increase the UCS of loess. The strength increases with the increase in CLP concentration and curing time. The UCS of loess treated with $2.0 \%$ CLPs $(1,497.84 \mathrm{kPa})$ was 3.04 times that of untreated loess $(491.97 \mathrm{kPa})$. The optimal concentration range for CLP application is $1.2-2.0 \%$, and the optimal curing time range is 7-14 days.

2) CLPs can improve the anti-disintegration property of loess. With an increase in CLP concentration, the stability index of loess was greatly increased, and the $1.6 \%$ CLP treatment showed the best anti-disintegration effect considering cost and benefit.

3) The SWCC index showed a higher saturated effective water content and lower dehumidification rate in treated loess compared with that in untreated loess. The treated loess showed a better ability to hold and retain water than untreated loess.

4) CLPs can reduce water evaporation from potted loess without inhibiting the germination rate of plant seeds. Under longterm conditions, CLPs can significantly promote plant growth due to their water retention capacity.

5) XRD, FTIR, and SEM showed that CLPs did not affect the mineral composition of loess nor did they cause major changes in the functional groups. However, the particles were more closely connected, and the contact mode changed. Thus, the porosity was reduced, and many pores were filled with gel and debris. CLPs stabilized loess through ion exchange, hydrogen bonding, and packing and filling.

6) CLPs not only improve the strength and disintegration resistance of loess but also have high water retention. Field tests showed that compared with untreated loess slopes, the slopes treated with CLPs had reduced soil erosion, which promoted vegetation recovery.

7) As a new type of soil stabilizer, CLPs have the following advantages: 1) They can be configured into a solution at normal atmospheric temperature $\left(15-20^{\circ} \mathrm{C}\right)$ and can be diluted to varying degrees. 2) They can be solidified at normal atmospheric temperature with high strength. 3) The concentration of CLP stock solution is only $2.0 \%$, the amount of CMC and PAM needed is small, and the cost/performance ratio is high. 


\section{DATA AVAILABILITY STATEMENT}

The raw data supporting the conclusion of this article will be made available by the authors, without undue reservation.

\section{AUTHOR CONTRIBUTIONS}

XZ: Conceptualization, Formal analysis, Data curation, Writing-review and editing, Methodology, Supervision. YZ: Writing-original draft, Writing_review and editing, Formal analysis, Visualization, Investigation. XP: Methodology, Writing-review and editing, Supervision, Resources, Funding

\section{REFERENCES}

Ahmed, A., and Issa, U. H. (2014). Stability of Soft clay Soil Stabilised with Recycled gypsum in a Wet Environment. Soils and Foundations 54, 405-416. doi:10.1016/j.sandf.2014.04.009

Al-mashhadani, M. M., Canpolat, O., Aygörmez, Y., Uysal, M., and Erdem, S. (2018). Mechanical and Microstructural Characterization of Fiber Reinforced Fly Ash Based Geopolymer Composites. Construction Building Mater. 167, 505-513. doi:10.1016/j.conbuildmat.2018.02.061

Behnood, A. (2018). Soil and clay Stabilization with Calcium- and Non-calciumbased Additives: A State-Of-The-Art Review of Challenges, Approaches and Techniques. Transportation Geotechnics 17, 14-32. doi:10.1016/ j.trgeo.2018.08.002

Bu, F., Liu, J., Bai, Y., Prasanna Kanungo, D., Song, Z., Kong, F., et al. (2019). Effects of the Preparation Conditions and Reinforcement Mechanism of Polyvinyl Acetate Soil Stabilizer. Polymers 11, 506-520. doi:10.3390/polym11030506

Chandler, N., Palson, J., and Burns, T. (2017). Capillary Rise experiment to Assess Effectiveness of an Enzyme Soil Stabilizer. Can. Geotech. J. 54, 1509-1517. doi:10.1139/cgj-2016-0511

Chang, I., Prasidhi, A. K., Im, J., Shin, H.-D., and Cho, G.-C. (2015). Soil Treatment Using Microbial Biopolymers for Anti-desertification Purposes. Geoderma 253254, 39-47. doi:10.1016/j.geoderma.2015.04.006

Chebbi, M., Guiras, H., and Jamei, M. (2020). Tensile Behaviour Analysis of Compacted Clayey Soil Reinforced with Natural and Synthetic Fibers: Effect of Initial Compaction Conditions. Eur. J. Environ. Civil Eng. 24, 354-380. doi:10.1080/19648189.2017.1384762

Chen, H., Zhang, X., Abla, M., Lü, D., Yan, R., Ren, Q., et al. (2018). Effects of Vegetation and Rainfall Types on Surface Runoff and Soil Erosion on Steep Slopes on the Loess Plateau, China. Catena 170, 141-149. doi:10.1016/ j.catena.2018.06.006

Choobbasti, A. J., and Kutanaei, S. S. (2017). Microstructure Characteristics of Cement-Stabilized sandy Soil Using Nanosilica. J. Rock Mech. Geotechnical Eng. 9, 981-988. doi:10.1016/j.jrmge.2017.03.015

Dehghan, H., Tabarsa, A., Latifi, N., and Bagheri, Y. (2019). Use of Xanthan and Guar Gums in Soil Strengthening. Clean. Techn Environ. Pol. 21, 155-165. doi:10.1007/s10098-018-1625-0

Duan, J., Liu, Y.-J., Tang, C.-J., Shi, Z.-H., and Yang, J. (2021a). Efficacy of Orchard Terrace Measures to Minimize Water Erosion Caused by Extreme Rainfall in the Hilly Region of China: Long-Term Continuous In Situ Observations. J. Environ. Manage. 278, 111537. doi:10.1016/j.jenvman.2020.111537

Eyo, E. U., Ng'ambi, S., and Abbey, S. J. (2020). An Overview of Soil-Water Characteristic Curves of Stabilised Soils and Their Influential Factors. J. King Saud Univ. - Eng. Sci. doi:10.1016/j.jksues.2020.07.013

Feng, L., Lin, H., Zhang, M., Guo, L., Jin, Z., and Liu, X. (2020). Development and Evolution of Loess Vertical Joints on the Chinese Loess Plateau at Different Spatiotemporal Scales. Eng. Geology. 265, 105372. doi:10.1016/j.enggeo.2019.105372

Fu, B.-J., Wang, Y.-F., Lu, Y.-H., He, C.-S., Chen, L.-D., and Song, C.-J. (2009). The Effects of Land-Use Combinations on Soil Erosion: a Case Study in the Loess Plateau of China. Prog. Phys. Geogr. Earth Environ. 33, 793-804. doi:10.1177/ 0309133309350264 acquisition. YD: Writing-review and editing, Visualization, Data curation.

\section{FUNDING}

This study was partially supported by the Major Program of the National Natural Science Foundation of China (Grant No. 41790445), the National Science Fund for Distinguished Young Scholars of China (Grant No. 41702335), and the National Key Research and Development Project (2018YFC1504702).

Ghasemzadeh, H., and Modiri, F. (2020). Application of Novel Persian Gum Hydrocolloid in Soil Stabilization. Carbohydr. Polym. 246, 116639. doi:10.1016/ j.carbpol.2020.116639

Hu, S., Qiu, H., Wang, N., Cui, Y., Wang, J., Wang, X., et al. (2020). The Influence of Loess Cave Development upon Landslides and Geomorphologic Evolution: A Case Study from the Northwest Loess Plateau, China. Geomorphology 359, 107167. doi:10.1016/j.geomorph.2020.107167

Jalal, F. E., Xu, Y., Jamhiri, B., and Memon, S. A. (2020). On the Recent Trends in Expansive Soil Stabilization Using Calcium-Based Stabilizer Materials (CSMs): a Comprehensive Review. Adv. Mater. Sci. Eng. 2020, 1-23. doi:10.1155/2020/ 1510969

James, J. (2020). Sugarcane Press Mud Modification of Expansive Soil Stabilized at Optimum Lime Content: Strength, Mineralogy and Microstructural Investigation. J. Rock Mech. Geotechnical Eng. 12, 395-402. doi:10.1016/ j.jrmge.2019.10.005

Keramatikerman, M., Chegenizadeh, A., and Nikraz, H. (2016). Effect of GGBFS and Lime Binders on the Engineering Properties of clay. Appl. Clay Sci. 132-133, 722-730. doi:10.1016/j.clay.2016.08.029

Krainiukov, A., Liu, J., Kravchenko, E., and Chang, D. (2020). Performance of Silty Sand Reinforced with Aqueous Solution of Polyvinyl Alcohol Subjected to Freeze-Thaw Cycles. Cold Regions Sci. Techn. 174, 103054. doi:10.1016/ j.coldregions.2020.103054

Kushwaha, S. S., Kishan, D., and Dindorkar, N. (2018). Stabilization of Expansive Soil Using Eko Soil Enzyme for Highway Embankment. Mater. Today Proc. 5, 19667-19679. doi:10.1016/j.matpr.2018.06.329

Latifi, N., Suksun, H., Meehan, C., Abd Majid, Z., Tahir, M. M., and Mohamad, E. T. (2017). Improvement of Problematic Soils with Biopolymer-An Environmentally Friendly Soil Stabilizer. J. Mater. Civil Eng. 29, 1-11. doi:10.1061/(ASCE)MT.1943-5533.0001706

Lei, X. (1988). The Types of Loess Pores in China and Their Relationship with Collapsibility. Sci. Chin. (Ser. B). 31, 1398-1411. doi:10.1360/zb1987-17-121309

Li, M., Zhang, X., Yang, Z., Yang, T., and Pei, X. (2020). The Rainfall Erosion Mechanism of High and Steep Slopes in Loess Tablelands Based on Experimental Methods and Optimized Control Measures. Bull. Eng. Geol. Environ. 79, 4671-4681. doi:10.1007/s10064-020-01854-3

Li, T., Zhao, L., Duan, H., Yang, Y., Wang, Y., and Wu, F. (2019). Exploring the Interaction of Surface Roughness and Slope Gradient in Controlling Rates of Soil Loss from Sloping farmland on the Loess Plateau of China. Hydrological Process. 34, 339-354. doi:10.1002/hyp.13588

Liu, G., Hu, F., Zheng, F., and Zhang, Q. (2019). Effects and Mechanisms of Erosion Control Techniques on Stairstep Cut-Slopes. Sci. Total Environ. 656, 307-315. doi:10.1016/j.scitotenv.2018.11.385

Liu, J., Shi, B., Jiang, H., Huang, H., Wang, G., and Kamai, T. (2011). Research on the Stabilization Treatment of clay Slope Topsoil by Organic Polymer Soil Stabilizer. Eng. Geology. 117, 114-120. doi:10.1016/j.enggeo.2010.10.011

Liu, Y., Zheng, W., Wang, Q., Cao, C., Chang, M., and Rocchi, I. (2020). Evaluating Sulfur-free Lignin as a Sustainable Additive for Soil Improvement against Frost Resistance. J. Clean. Prod. 251, 119504. doi:10.1016/j.jclepro.2019.119504

Özen, İ., Okyay, G., and Ulaş, A. (2018). Coating of Nonwovens with Potassium Nitrate Containing Carboxymethyl Cellulose for Efficient Water and 
Fertilizer Management. Cellulose 25, 1527-1538. doi:10.1007/s10570-018$1655-0$

Peng, J., Sun, P., Igwe, O., and Li, X. a. (2018). Loess Caves, a Special Kind of Geohazard on Loess Plateau, Northwestern China. Eng. Geology. 236, 79-88. doi:10.1016/j.enggeo.2017.08.012

Reza Golhashem, M., and Uygar, E. (2020). Volume Change and Compressive Strength of an Alluvial Soil Stabilized with Butyl Acrylate and Styrene. Construction Building Mater. 255, 119352. doi:10.1016/j.conbuildmat.2020.119352

Song, Z., Liu, J., Bai, Y., Wei, J., Li, D., Wang, Q., et al. (2019). Laboratory and Field Experiments on the Effect of Vinyl Acetate Polymer-Reinforced Soil. Appl. Sci. 9, 208-222. doi:10.3390/app9010208

Tang, B., Jiao, J., Zhang, Y., Chen, Y., Wang, N., and Bai, L. (2020). The Magnitude of Soil Erosion on Hillslopes with Different Land Use Patterns under an Extreme Rainstorm on the Northern Loess Plateau, China. Soil Tillage Res. 204, 104716. doi:10.1016/j.still.2020.104716

Tingle, J. S., Newman, J. K., Larson, S. L., Weiss, C. A., and Rushing, J. F. (2007). Stabilization Mechanisms of Nontraditional Additives. Transportation Res. Rec. 1989-2, 59-67. doi:10.3141/1989-49

van Genuchten, M. T. (1980). A Closed-form Equation for Predicting the Hydraulic Conductivity of Unsaturated Soils. Soil Sci. Soc. America J. 44, 892-898. doi:10.2136/sssaj1980.03615995004400050002x

Vanapalli, S. K., Fredlund, D. G., and Pufahl, D. E. (1999). The Influence of Soil Structure and Stress History on the Soil-Water Characteristics of a Compacted till. Géotechnique 49, 143-159. doi:10.1680/geot.1999.49.2.143

Wang, Y., Soga, K., Dejong, J. T., and Kabla, A. J. (2019). A Microfluidic Chip and its Use in Characterising the Particle-Scale Behaviour of Microbial-Induced Calcium Carbonate Precipitation (MICP). Géotechnique 69, 1086-1094. doi:10.1680/jgeot.18.P.031

Wei, W., Chen, L., Fu, B., Huang, Z., Wu, D., and Gui, L. (2007). The Effect of Land Uses and Rainfall Regimes on Runoff and Soil Erosion in the Semi-arid Loess Hilly Area, China. J. Hydrol. 335, 247-258. doi:10.1016/j.jhydrol.2006.11.016

Wen, Y., Kasielke, T., Li, H., Zhang, B., and Zepp, H. (2021). May Agricultural Terraces Induce Gully Erosion? A Case Study from the Black Soil Region of Northeast China. Sci. Total Environ. 750, 141715. doi:10.1016/j.scitotenv.2020.141715

White, N. F., Duke, H. R., Sunada, D. K., and Corey, A. T. (1970). Physics of Desaturation in Porous Materials. J. Irrig. Drain. Div. 96, 165-191. doi:10.1061/ JRCEA4.0000716

Wu, Z.-j., Zhao, D.-y., Che, A.-1., Chen, D.-w., and Liang, C. (2020). Dynamic Response Characteristics and Failure Mode of Slopes on the Loess Tableland Using a Shaking-Table Model Test. Landslides 17, 1561-1575. doi:10.1007/ s10346-020-01373-y

Xu, H., Miao, J., Chen, P., Zhan, L., and Wang, Y.-z. (2019). Chemical and Geotechnical Properties of Solidified/stabilized MSWI Fly Ash Disposed at a Landfill in China. Eng. Geology. 255, 59-68. doi:10.1016/j.enggeo.2019.04.019

Yan, Y., Zhen, H., Zhai, X., Li, J., Hu, W., Ding, C., et al. (2021). The Role of Vegetation on Earth Bunds in Mitigating Soil Erosion in Mollisols Region of Northeast China. Catena 196, 104927. doi:10.1016/j.catena.2020.104927

Yang, Q.-w., Pei, X.-j., and Huang, R.-q. (2019). Impact of Polymer Mixtures on the Stabilization and Erosion Control of Silty Sand Slope. J. Mt. Sci. 16, 470-485. doi:10.1007/s11629-018-4905-6
Yoobanpot, N., Jamsawang, P., Poorahong, H., Jongpradist, P., and Likitlersuang, S. (2020). Multiscale Laboratory Investigation of the Mechanical and Microstructural Properties of Dredged Sediments Stabilized with Cement and Fly Ash. Eng. Geology. 267, 105491. doi:10.1016/j.enggeo.2020.105491

Zhai, Q., Rahardjo, H., Satyanaga, A., and Dai, G. (2020). Estimation of the SoilWater Characteristic Curve from the Grain Size Distribution of Coarse-Grained Soils. Eng. Geology. 267, 105502. doi:10.1016/j.enggeo.2020.105502

Zhang, L., Qi, S., Ma, L., Guo, S., Li, Z., Li, G., et al. (2020b). Three-dimensional Pore Characterization of Intact Loess and Compacted Loess with Micron Scale Computed Tomography and Mercury Intrusion Porosimetry. Sci. Rep. 10, 8511. doi:10.1038/s41598-020-65302-8

Zhang, T., Cai, G., Liu, S., and Puppala, A. J. (2016). Engineering Properties and Microstructural Characteristics of Foundation silt Stabilized by Lignin-Based Industrial By-Product. KSCE J. Civ. Eng. 20, 2725-2736. doi:10.1007/s12205016-1325-4

Zhang, T., Yang, Y.-L., and Liu, S.-Y. (2020a). Application of Biomass By-Product Lignin Stabilized Soils as Sustainable Geomaterials: A Review. Sci. Total Environ. 728, 138830. doi:10.1016/j.scitotenv.2020.138830

Zhang, Z., Gao, W., Zhang, Z., Xiao-yu, T., and Jun, W. (2020). Evolution of Particle Disintegration of Red sandstone Using Weibull Distribution. Rock Soil Mech. 41, 877-885. doi:10.16285/j.rsm.2019.0926

Zhang, Z., Zhang, H., Zhang, J., and Chai, M. (2019). Effectiveness of Ionic Polymer Soil Stabilizers on Warm Frozen Soil. KSCE J. Civ. Eng. 23, 2867-2876. doi:10.1007/s12205-019-0561-9

Zhao, G., Mu, X., Wen, Z., Wang, F., and Gao, P. (2013). Soil Erosion, Conservation, and Eco-Environment Changes in the Loess Plateau of China. Land Degrad. Develop. 24, 499-510. doi:10.1002/ldr.2246

Zhao, Q., Li, D., Zhuo, M., Guo, T., Liao, Y., and Xie, Z. (2015). Effects of Rainfall Intensity and Slope Gradient on Erosion Characteristics of the Red Soil Slope. Stoch Environ. Res. Risk Assess. 29, 609-621. doi:10.1007/ s00477-014-0896-1

Conflict of Interest: The authors declare that the research was conducted in the absence of any commercial or financial relationships that could be construed as a potential conflict of interest.

Publisher's Note: All claims expressed in this article are solely those of the authors and do not necessarily represent those of their affiliated organizations, or those of the publisher, the editors and the reviewers. Any product that may be evaluated in this article, or claim that may be made by its manufacturer, is not guaranteed or endorsed by the publisher.

Copyright (๑) 2021 Zhang, Zhong, Pei and Duan. This is an open-access article distributed under the terms of the Creative Commons Attribution License (CC BY). The use, distribution or reproduction in other forums is permitted, provided the original author(s) and the copyright owner(s) are credited and that the original publication in this journal is cited, in accordance with accepted academic practice. No use, distribution or reproduction is permitted which does not comply with these terms. 